\title{
O ECLETISMO FILOSÓFICO DE HORÁCIO
}

Enio Aloisio FONDA ${ }^{1}$

- RESUMO: Tentativa de expor o ecletismo filosófico estóico epicurista na obra de Horácio.

- PALAVRAS-CHAVE: Literatura latina; filosofia helênica; epicurismo; estoicismo.

Os aspectos filosóficos dos clássicos latinos têm sido, geralmente, abordados por homens de Letras que não possuem a necessária e indispensável formação filosófica strictu sensu para a abordagem de assuntos de tão específica natureza.

É sabido que o real e efetivo domínio de uma língua qualquer é apenas um pressuposto imprescindível para o estudo de determinado autor, e que, para tratá-lo sob o enfoque específico, é preciso que o estudioso tenha uma formação também específica; é o que se configura no caso de Horácio como adepto dessa ou daquela corrente filosófica. Assim sendo, encetei o presente trabalho, procurando apresentá-lo não como professor de Língua e Literatura Latina, mas como formado em Filosofia também.

1 Professor Titular de Língua e Literatura Latina - Faculdade de Ciências e Letras - UNESP 19800-000 - Assis - SP. 
De um exame atento das passagens da obra de Horácio, em que ele próprio se refere a seus estudos de filosofia, resultará que o Poeta se dedicara sobretudo às questões éticas, pois afirma que, em sua juventude, demorou-se em Atenas a fim de poder discernir o justo do injusto, o verdadeiro do falso (Epist. II, 2, 44-45). Noutra passagem, afirma que, ainda jovem, na propriedade rural que tinha na região sabina, soía saber de seus vizinhos se os homens eram felizes pelos bens materiais ou, antes, pelos dotes morais; se, no estabelecimento das amizades importava mais o interesse ou o desprendimento; qual era a natureza do bem, e no que consistia, afinal, o sumo bem (Sat. II, 6, 75-76). Por fim, reconhece pesada a duração dos momentos que o impediam de se dedicar à propagação dos preceitos da moral civil (Epist, I, 1, 25-25).

Se é verdade que Horácio se dedicou ao estudo da filosofia mormente por causa da ética, a fim de conhecer os meios para chegar à vida feliz, visto que todas as questões de ética filosófica têm isso por objetivo, não é, contudo, possível que tivesse descurado por completo das questões relativas à natureza (chamadas físicas pelos antigos, de acordo com a terminologia aristotélica). Isso, já pelo fato de as questões relativas à natureza estarem estritamente relacionadas com as morais. Diga-se, porém, que Horácio tratou delas muito resumidamente e sem maior detença.

Isso posto, interessará saber quais filósofos tomara Horácio como guias para as suas perquirições. A esse respeito, aliás, já se tratou com freqüência e de maneiras discordantes, e não sem disparates.

Um juízo cuidadoso pode admitir-lhe, sem dúvida alguma, conhecimentos de duas escolas filosóficas apenas: a estóica e a epicurista, tendo em vista o fato de o Poeta ter levado em consideração, unicamente, as doutrinas das duas escolas referidas, discorrendo sobre elas e expondolhes os princípios. Tanto isso é verdade que, na passagem em que, propositadamente, alude aos sistemas que costumava seguir em seus estudos filosóficos, menciona só as duas referidas escolas (Epist. I, 1 16-19).

\section{O ecletismo horaciano}

Os espíritos mais sensatos, em Roma, a exemplo do que acontecia na Grécia, dividiam-se em duas grandes escolas de pensamento: ou epicurista, ou estóica. Não é aqui o caso de lhes definir as doutrinas, mas sim de pressupor, da parte do interessado leitor, conhecimentos sobre as duas correntes então em voga.

É inegável a influência que ambas exerceram sobre Horácio, apesar de seu indiscutível propósito em conservar sua independência, que se 
revela na resposta que dá à pergunta que lhe poderia ser dirigida acerca do sistema filosófico por ele aceito como norma:

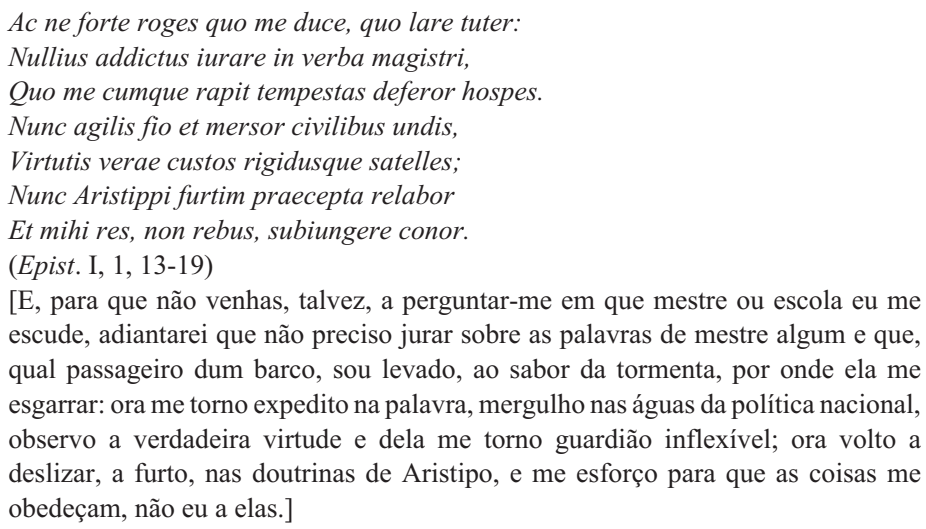

Em resumo: nem epicurista, nem estóico; sem dogmatismos, e livre de quaisquer vínculos ideológicos; adaptando as coisas em seu proveito, de acordo com as necessidades das circunstâncias e jamais acomodando-se a elas.

Atente-se aqui que os versos 16 e 17 acima são uma explícita alusão aos estóicos que queriam fossem seus adeptos agiles, quer dizer, desembaraçados (desimpedidos) nas palavras e devotados às batalhas civis, e, sobretudo, cultores da verdadeira virtude, unicamente por amor a ela. Por sua vez, os versos 18 e 19 referem-se não só a Aristipo, como também ao seu adepto Epicuro.

\section{Juízo de Horácio acerca da filosofia estóica e epicurista}

Uma leitura apenas superficial da obra horaciana poderá resultar na aceitação de que o Poeta ficou distanciado dos estóicos pelo fato de, em muitas passagens, debater cerebrinamente com eles. Assim, por exemplo, afirma ser Fábio Estóico loquaz (Sat. I, 1,14) e desregrado (Sat. I, 2,134); Crispino, remelento, vale dizer, inepto, pedante e de mau gosto (Sat. I, 1,120 e I, 3,138); alhures zomba da incrível falta de reflexão do mesmo, quando escreve para provocá-lo, nestes termos:

...Detur nobis locus, hora,

Custodes: videamus uter plus scribere possit. 
(Sat. I, 4,15-16)

[Fixem-se o lugar, a hora e os vigias; veremos qual dos dois escreve mais.]

É sabido que Crispino dera-se, a si próprio, o epíteto de aretólogo (estudioso da virtude); ora, a fim de escarnecer da classe dos aretólogos, Horácio faz constar exatamente a este no séquito de um rei daqueles que, por um quarto de asse, iam enxaguar-se nos banhos públicos (Sat. I, 3, 136-138). Volta a descarregar sobre ele seu humor, quando escreve que o porteiro que sempre ouvia as declamações do seu amo (Crispino), tornou-se, ele também, semifilósofo, transmitindo a outros escravos, seus iguais na desventura, os preceitos do estoicismo aprendidos de seu amo (Sat. II, 7). Nem sequer poupa a Estertínio que, segundo a tradição, seria autor de 220 livros sobre filosofia estóica. De fato, sob o disfarce de um elogio, Horácio, que já chamara a Estertínio de oitavo entre os sábios (Sat. II, 3, 296), passa a tecer-lhe dura crítica:

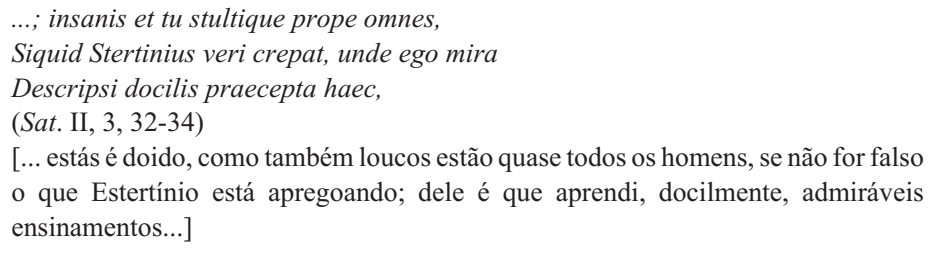

Em Epist. I, 12, 20, se refere, não sem certa ironia, ao "Stertinium cumen" (agudeza, subtileza do espírito de Estertínio) em delírios.

Horácio nota com prazer, em Damasipo: a tentativa de suicídio por ter malversado seus próprios bens; o hábito dos estóicos de deixar crescer a barba, a maneira desusada de suas conversas e certa animosidade em seus debates (Sat. II, 3,1 8-20).

O Poeta, a par de ridicularizar uns extravagantes adeptos do estoicismo, zomba também de certos preceitos deste, quando, em suas Sátiras, assevera:

1 - que todo néscio é um louco (Sat. II, 3, 320-321);

2 - que só o sábio é livre (Sat. II, 7, 83);

3 - que só o sábio faz todas as coisas do melhor modo possível (Sat. II, 3, 124-125).

Não deixa também de reprovar, severamente, aquele célebre paradoxo dos estóicos, segundo o qual todos os erros, na sua intensidade, são idênticos e não apenas semelhantes (Sat. I, 3, 96-98 e 115-117). 
Esse juízo estóico acerca dos erros humanos estava tornando inabaláveis, em suas convicções, os seguidores da doutrina de Zenão no julgamento da fraqueza humana, tão em desacordo com a natureza individual de Horácio, tendente à extrema clemência e benignidade. Apesar disso, seria de tudo temerário concluir-se, dessas premissas, que Horácio desprezasse o estoicismo. E, se é verdade que o Poeta zomba de Fábio, Crispino, Estertínio, Damasipo e de outros estóicos, pelo fato de diferirem dos demais homens finos e cultos da época, não deixa, todavia, de aludir com admiração profunda a personagens que se integraram naquele sistema filosófico. Prova disso é a honra que tributa devidamente a Panécio, amigo de Cipião Africano e de Lélio, chamando-o nobre, bem como a inclusão de Catão de Útica no rol de cidadãos romanos mais distintos (Carm. I, 12, 32-36 e II, 21-24). Não se poupa de falar com certo respeito, embora só ocasionalmente, também de Bruto, sob cujo comando estivera, quando tribuno militar em suas hostes.

O que admira é também o fato de não se mostrar irremissível antagonista dos paradoxos estóicos. De fato, como Damasipo afirmasse haver muitos a viver subjugados pelo vício da avareza, da ambição política, da luxúria, da inconstância no amar e da superstição, assim também Horácio os define como estultos e ociosos, quando declara:

Virtus est vitium fugere et sapientia prima

Stultitia caruisse.

(Epist. I, 1, 41-42)

[Virtude é fugir do vício, e suma sabedoria, estar com juízo.]

É de se levar em conta, também, o fato de Horácio, não raro, ter-se valido de certos chavões comuníssimos a Damasipo, tal como enlouquecer (desvairar), significando transigir aos vícios, e são, correspondendo a "estado de quem está dotado de virtudes" (Sat. I, 2, 49; 4, 27 e 129; 5, 82). Como, finalmente, é também digno de nota o caso de não rejeitar, cabalmente, a opinião do escravo Davo, segundo o qual, os homens entregues aos prazeres se tornam escravos destes. Nesse particular, Horácio nos ensina que ninguém goza da verdadeira liberdade, se não tiver domínio sobre si próprio (Epist. I, 2, 63-64).

\section{Juízos de Horácio acerca das questões físicas estóico-epicuristas em relação à natureza}


Para se conhecer com mais apuro o que Horácio hauriu das doutrinas epicuristas e estóicas, e no que ele com elas concorde e delas discorde, torna-se indispensável expor suas opiniões acerca da natureza, bem como seus argumentos éticos sobre o mesmo assunto, e compará-las com os ensinamentos das duas escolas filosóficas citadas. Detenhamo-nos, pois, com cuidado, sobre a seguinte passagem:

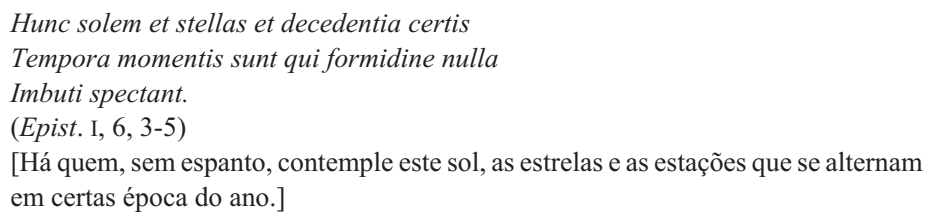

Não pode lavrar dúvida de que Horácio queria, com isso, especificar aqueles que, com a inteligência e certo grau de saber, souberam superar o medo pelos fenômenos extraordinários do céu, isto é, os epicuristas. Estes, na verdade, eram de opinião de que o sol, a lua, as estrelas e os demais corpos celestes não passavam de corpos naturais e forças surgidas da própria natureza; com isso, pretendiam libertar os homens das superstições e do medo. E, neste particular, não há sombra de dúvida de que Horácio lhes desse plena razão.

Do mesmo modo, Horácio concorda com Epicuro, quando menospreza os prodígios e os oráculos, o que se evidencia na passagem em que, durante sua viagem para Brundísio, a cidade de Egnácia provoca-lhe riso e gracejo por suas absurdas crendeirices (Sat. I, 5, 97-100). Mofa também de uma certa velha, de nome Sabela, que, quando Horácio criança ainda, lhe predissera:

Hunc neque dira venena nec hosticus auferet ensis,

Nec laterum dolor aut tussis nec tarda podagra:

Garrulus hunc quando consumet cumque : loquaces,

Si sapiat, vitet simul atque adoleverit aetas.

(sat. I, 9, 31-34)

[Nem o veneno terrível, nem a gota nos pés exterminará esta criança; mas, um dia, um tagarela acabará com ela. Logo que sua idade avançar, quando já souber discernir, deverá evitar os paroleiros.]

Numa outra passagem declara que todos deveriam empenhar-se em desprezar e escarnecer os "sonhos, os temores mágicos (fantasmas), os milagres, os feiticeiros, os espetros noturnos, os prodígios tessálicos" (Epist. II, 2, 208-209). Assim também apouca a arte de Apolo: a adivinhação (Sat. II, 5, 59-60). Horácio segue igualmente a doutrina epicurista no que diz respeito à propagação do gênero humano e a sua lenta mas 
progressiva marcha de aperfeiçoamento natural (evolução), tão bem consolidada no De rerum natura, de Lucrécio, e refletida em Sat. I, 3, 99-102 e 109-110. Afasta-se, contudo, de Epicuro e Lucrécio quanto à origem da linguagem. É sabido que ambos consideravam a linguagem decorrência espontânea própria à natureza humana, não passando, portanto, em sua essência, do latir dos caninos, do relinchar dos eqüinos e da emissão de sons de outros irracionais, exceto no que diz respeito à variedade e cópia destes mesmos sons. Contrariamente, Horácio sustentava que a linguagem humana era, na verdade, o resultado de um ato pensado e de progressivas descobertas e gradativos aprimoramentos (Sat. I, 3, 103-104). Horácio procura, com essas concepções que tem dos homens primevos, demonstrar que a justiça não aflorou espontaneamente, mas é, inegavelmente, uma obra de criação intelectual. De resto, parece que assim pensasse a esse respeito o próprio Lucrécio e, sem dúvida nenhuma, também Epicuro, em contraposição aos estóicos que ensinavam o justo existir por natureza e não por um conjunto de artificiosas convenções de ordem ético-moral.

Alhures, ao tratar de problemas atinentes à física, inoniza Árquita, filósofo pitagórico de Tarento, por seu inútil desvelo em querer desvendar os mistérios da natureza (Carm. I, 28, 4-6); como também menospreza as fúteis ninharias da perquirição dos fenômenos da natureza (Epist. I, $12,16-19)$

\section{Juízos de Horácio acerca da alma humana e seus nexos com a doutrina epicurista}

Não há como negar que a crença de horácio quanto à natureza da alma humana resvala, sem contornos, na doutrina epicurista, segundo a qual há mundos infinitos, as almas e os corpos seriam compostos de átomos dispostos de tal modo a originar a vida e os sentidos, e que, ao se desagregarem, causam o fim da vida e, conseqüentemente, dos próprios sentidos; daí o destemor diante da morte, justamente por carecer ela, por completo, do conjunto das funções orgânicas sensitivas. Epícuro, na verdade, ensinava: "Habitua-te a pensar que a morte nada é para nós, visto que todo o mal e todo o bem se encontram na sensibilidade: e a morte é a privação da sensibilidade". Por conseqüência analógica dessa concepção, Horácio descartaria a imortalidade da alma. Efetivamente, as inúmeras passagens, nas quais Horácio faz referência a fatos respeitantes aos já falecidos, não distoam dessa descrença. Tanto é verdade que embora mencione "a pobre morada de Plutão" (Carm. I, 4, 17), "Mercúrio, con- 
dutor de almas" (Carm. I, 10, 17-18), o "barco de Caronte" (Carm. II, 3, 29), ou o "juízo solene de Minos" (Carm. IV, 7, 21-22) e, ainda "os tardios destinos na região dos mortos" (Carm. III, 11, 28-29), isso tudo não passaria de meras figuras poéticas. A ode (Carm. IV, 7) revela, toda ela, e de modo insofismável, a descrença de Horácio na imortalidade da alma. Há nela um gama de melancolia, como a lamentar essa triste realidade: os mortos, infelizmente, não voltam mais. E, se aqui e acolá, Horácio faz alusão à imortalidade, não quer com isso admitir uma vida no além túmu$l o$, mas sim tão-só a fama eterna que um ou outro possa vir a alcançar entre os pósteros, máxime aqueles varões ilustres que venham a merecer, da parte dos poetas, seus encômios imorredouros (Carm. IV, 8, 22, 24 e 28; $9,25-28)$. Nessa perspectiva é que também os poetas se imortalizam por seus versos enquanto contribuem a perpetuar com eles os feitos extraordinários das figuras insignes de uma nação; e a consciência disso move-o à inspiração de sua própria imortalidade na memória dos porvindouros (Carm. II, 20, 5-8; III, 30, 6-9), e a desprezar as honras fúnebres, que sempre reputou inúteis (Carm. II, 20, 23-24). Não se pode, porém, a meu ver, confundir imortalidade individual da alma com vida eterna tal qual é concebida pelo dogma cristão, por exemplo, ou pela doutrina do islamismo que admite a continuidade da fruição, por parte dos eleitos, do gozo hedonístico dos prazeres próprios da vida terrena. Horácio, no seu caso, poderia, perfeitamente, não admitir uma vida biológica além túmulo, na acepção hedonística do termo, mas nem por isso teria negado a sobrevivência da alma.

Juízos de Horácio sobre os deuses

Horácio, como Epicuro e Lucrécio, desaprova a religião do tempo, com todas as superstições, todas as inferioridades de sentimento e de inteligência, que fazia nascer e, cuidadosamente, conservava na alma dos fiéis. Contudo, não é de se admirar que ele não combatesse, abertamente, as crenças generalizadas nos deuses e que, pelo contrário, lhes desse até apoio, mencionando, com respeito, em inúmeras passagens da sua obra, Apolo, Ceres, Diana, Juno, Marte, Mercúrio, Minerva, Netuno, Vesta, Vulcano e outros, bem como os deuses tutelares da casa e do lar (Penates e Lares), e Gênio que, segundo os antigos, presidia ao destino de cada um; tudo de acordo com a crença mais chã da plebe.

Horácio não se omite também, seguindo sempre o costume do povo, de fazer preces, oferecer sacrifícios, comemorar os dias festivos prescritos no calendário da época. Tanto isso é verdade que, em sua obra, encontram-se preces (Carm. I, 35; Epist. I, 18); e, de Carm. I, 4; I, 7; I, 36; III, 8; III, 14 e III, 18 pode-se concluir que não só ele próprio oferecia sacrifícios, mas convidava os outros a fazê-lo também. Em Carm. III, 28 temos, finalmente, a prova de sua observância dos dias de preceito 
religioso. Acresça-se, ainda, o fato de o Poeta ter composto hinos em louvor das mais diversas divindades: Apolo e Diana (Carm. I, 21); Baco (Carm. II, 19 e III, 25); Fortuna (Carm. I, 35); Mercúrio (Carm. I, 10 e III, 11) e, sobretudo, o Carmen Saeculare.

É oportuno lembrar também que Horácio procura emendar opiniões errôneas acerca da religião, o que não acontece com os detratores da fé popular. Sirva de exemplo apenas um passo, no qual o Poeta procura fazer ver que os deuses não dão importância à magnificência dos sacrifícios que se lhes oferecem, mas antes à intenção com que são oferecidos. É o que resulta dos versos seguintes, quando Horácio consola Fídele da exigüidade do sacrifício que oferecera:

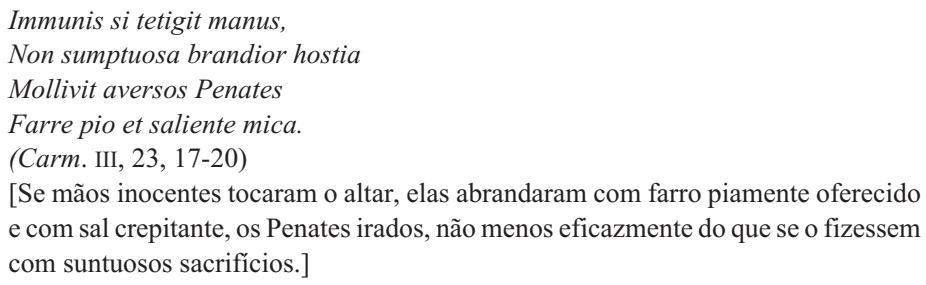

[Se mãos inocentes tocaram o altar, elas abrandaram com farro piamente oferecido e com sal crepitante, os Penates irados, não menos eficazmente do que se o fizessem com suntuosos sacrifícios.]

Contudo, é inegável que Horácio se tenha preocupado, como todo intelectual da época, com as crenças supersticiosas enraizadas nas camadas menos avisadas e numa maioria ingenuamente crente. Não por isso, porém, pertence ele ao rol dos ateus declarados. Tudo indica que o Poeta admitia haver uma única divindade suprema a reger os negócios dos homens e dos demais deuses:

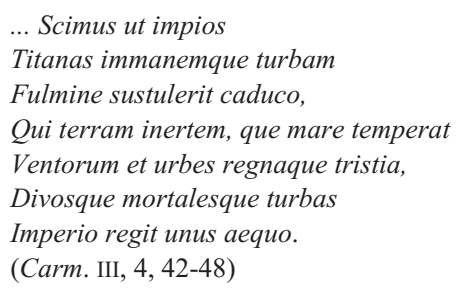


(Carm. I, 12, 14-18)

[Que direi antes senão render homenagens a Júpiter que governa as coisas divinas e humanas, que regula o mar e as terras e o inverno por meio de estações variadas? Donde advém que nada foi criado maior do que ele, e nada existe de semelhante ou igual a ele.]

Gentis humanae pater atque custos.

[Pai e conservador da raça humana.]

O fato de mencionar Minerva como a mais honrada divindade ao lado de Júpiter (Carm. I, 12, 19-20; III, 4, 57) não significa que o Poeta admitisse a existência paralela de outra deidade suprema, visto que, com isso, nada mais pretende designar senão a sabedoria e a providência do próprio Júpiter. O mesmo vale com relação a outros numes, que o Poeta faz surgir em abundância e que nada mais exprimem a não ser as multímodas qualidades e propriedades teofânicas de Iuppiter optimus et maxi$m u s$, que não leva o tempo na inoperância, mas que atende às necessidades de todos, recompensa os povos que o veneram com devoção e respeito, e pune aos que o negligenciam.

Horácio, atendendo ao apelo de Otaviano, preocupado em restabelecer no meio do povo romano a primitiva religiosidade dos antepassados, dá a sua colaboração para a restauração dos antigos costumes e tradições, da crença religiosa, do patriotismo, dos valores morais e das virtudes cívicas, compondo, para tal fim, muitos dos seus carmes. Encontramolo, então, arrojando-se contra a irreligiosidade, encorajando a reconstrução dos templos ruídos em virtude da vetustez ou por incêndios ( $\mathrm{Carm}$. II, 5 e III, 6).

\section{Um aparente contraste}

Três passagens horacianas, pelo menos, dão azo a que se afirme a crença do Poeta: a do castigo individual dos ímpios (Carm. III, 1, 16-21); a da consumição do ímpio e, não raro, também do inocente que se lhe ajuntou (Carm. III, 2, 30-32); a da recompensa, para os íntegros, com uma vida feliz e serena (Carm. I, 22, 1-4). Isso, no entanto, poderá contrastar com a passagem seguinte :

...nanque deos didici securum agere aevum,

(Sat. I, 5, 101)

[... porque aprendi que os deuses passam o tempo em tranqüila indiferença.], que está em concordância de sentido e forma com os versos de Lucrécio: 
Nam, bene qui didicere deos securum agere aevum...

(De rer. nat. V, 82 e VI. 58)

[De fato, aqueles que aprenderam que os deuses levam uma vida sossegada....]

Essa coincidência ad litteram et ad sensum poderá levar alguém a afirmar que Horácio, seguindo as doutrinas de Epicuro e Lucrécio, tenha jamais admitido o providencialismo. Tal afirmação, porém, sucumbe por si só, desde que a aludida passagem da Sat. I, 5, 101 seja interpretada devidamente. De fato, se acompanharmos, como convém o sentido dos pensamentos nela contidos, concluiremos que Horácio reporta o verso de Lucrécio (De rer. nat. V, 83 e VI, 58), unicamente, para demonstrar que os deuses não alteram as leis da natureza (nihil contra naturam fit) e que, se a mesma, efetivamente, os apresenta, eles se devem, intrinsecamente, aos numes celestes. Por onde, a expressão deos agere securum aevum deve se entender somente relacionada às leis da natureza irracional, e não às vicissitudes dos povos (nações) e dos indivíduos (cidadãos), singularmente.

Seria temeridade defender sem mais nem menos o ponto de vista dos que exaltam o providencialismo indiscriminado de Horácio, como também afirmar com outros muitos que o Poeta tenha desprezado qualquer sentimento religioso até o momento da composição da ode ( $\mathrm{Carm}$. I,34) em que se desdiz, convencido de seus erros epicuristas :

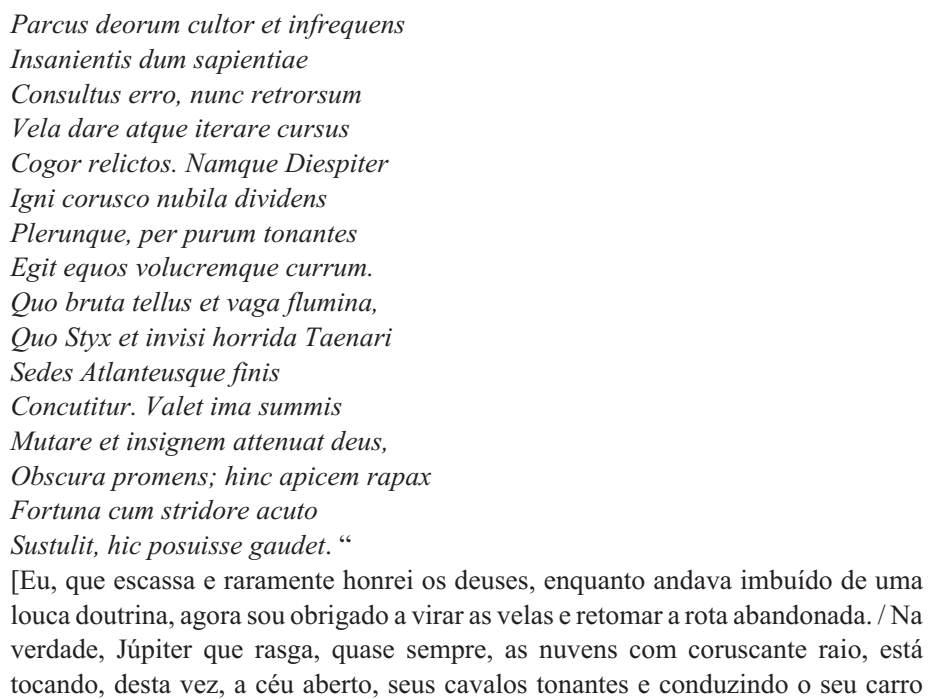


alado, / pelo qual se abalam a terra imóvel, os rios corredios, o Estige, a horrível morada do odioso Ténaro e mesmo os confins do mundo. / Deus (Júpiter) pode transformar em grandes as coisas mais rasteiras, e rebaixa o poderoso elevando o humilde. A fortuna rapace folga em colocar sobre a outra cabeça a coroa que arrancou de outrem, sob o agudo adejo de suas asas.)

É inegável que, aqui, a insaniens sapientia (endoidecedora filosofia) é a própria doutrina de Epicuro, como também não se pode negar que Horácio tenha, não raro, confessado a sua piedade e lealdade às tradições religiosas nacionais em suas composições anteriores ao ano de 23 a.C., data da ode em questão. Há filólogos que julgam serem as seis primeiras odes do livro terceiro (Carm. III, 1-6), nas quais o Poeta expõe suas próprias opiniões acerca dos deuses, já dos anos 28-25 a.C.; a ode doze do livro primeiro (Carm. I, 12), do ano 26 a.C., o epodo dezesseis (Epod. 17), dos anos 32-30 a.C., e que, por isso mesmo, Horácio teria sofrido influências das doutrinas epicuristas só por um breve lapso de tempo.

Me pinguem et nitidum bene curata cute vises,

Cum ridere vis, Epicuri de grege porcum.

(Epist. I, 4,15-16)

[Se quiseres rir mesmo, espia como minha pele está bem tratada e toda cheirosa; mira como estou nédio, feito um porco da manada de Epicuro.]

\section{Outros pontos de vista sobre o Carm. I, 34}

São os mais diversos os pontos de vista que por parte dos estudiosos do assunto têm sido defendidos em relação à ode horaciana acima enfocada. Procurar-se-á alinhá-los e condensá-los na medida em que esses mesmos pontos de vista constituem, de fato, correntes críticas e tenham adeptos.

Para uns, a ode não seria nenhuma profissão de fé; nem uma velada alusão a qualquer vicissitude histórica - queda de Titidates (cf. Carm. I, 26,5) ou derrota de Antônio - , querendo, com isso alertar os leitores da volubilidade do destino (Fortuna) e da efemeridade e caducidade do que o homem possa vir a alcançar.

Para outros, seria o revide categórico à temerária inquirição de Lucrécio:

Denique cur numquam caelo iacit undique puro

Iuppiter in terras fulmen sonitusque profundit?

(De rer. nat. VI, 399-400) 
[Finalmente, por que é que Júpiter não lança dum céu inteiramente limpo e espalha pelas terras o raio e seu trovão?]

Nem faltam aqueles para os quais a ode em questão não passaria de um gracejo que, embora escrito em primeira pessoa, não se refere a Horácio: seria pueril que ele renunciasse às suas opiniões unicamente por causa de um raio caído a céu sereno. E então? Eis: há alguns que se dizem cépticos, mas que no primeiro contratempo recorrem aos deuses; mas, se instados a respeito, respondem que isso tudo os espanta e amedronta a aceitá-los. Outros, enfim, defendem a opinião de que Horácio compôs algumas odes a pedido de Augusto, que desejava restaurar em Roma a religião e os antigos costumes.

Custa admitir a opinião de outros, segundo os quais Horácio, ao abordar, mesmo com certa freqüência, motivos de natureza religiosa, fê-lo unicamente em conseqüência da sua vocação lírica e astro poético, excluindo-lhe toda e qualquer tendência de ordem transcendente.

FONDA, E. A. Horace's philosophical eclecticism. Trans/Form/Ação (São Paulo), v.20, p.51-62, 1997.

- ABSTRACT: Attempt of a exposition of the epicurian-stoic philosophical ecletism in the work of Horatius.

- KEYWORDS: Latine literature; hellenic philosophy; epicurianism; stoicism.

\section{Referências bibliográficas}

As citações e referências à obra de Horácio (Epodos, Sátiras, Odes, Epístolas) ocorrentes no presente trabalho foram extraídas de:

KIESSLING, A. Q. Horatius Flaccus. 3.auflage. Berlin: Weidmannsche Buchhandlung, 1898. 